\title{
Risk of accidents in drivers with epilepsy
}

\author{
Joan Taylor, David Chadwick, Tony Johnson
}

\begin{abstract}
Objective-To estimate the risks of road traffic accidents over a period of three years in drivers with a history of single seizures or epilepsy, and to compare them with a cohort of drivers followed up by the Transport Research Laboratory (TRL).
\end{abstract}

Design-A retrospective survey of driving and accident experience by self-completion questionnaire.

Subjects-16 958 drivers with a previous history of epilepsy responding to the survey and $\mathbf{8 8 8 8}$ non-epileptic drivers responding to a TRL survey.

Main outcome measures-The risk of any accident, any accident producing an injury, and any accident producing a serious injury, over a three year period.

Results-After adjustment for differences in age, sex, driving experience, and mileage between the two populations there was no evidence of any overall increase in risk of accidents in the population of drivers with a history of epilepsy. However, there was evidence of an increased risk of more severe accidents in the population with epilepsy. The risk was increased by about $40 \%$ for serious injuries and there was evidence of a twofold risk of increase in non-driver fatalities. These increases seem largely explicable by the occurrence of seizures in this population during the three years of driving that the survey covered.

Conclusions-The acceptability of driving for people with a history of epilepsy should be determined by an acceptable risk of accidents resulting in injury or serious injury rather than overall accident rates. As people with epilepsy can now drive after a 12 month seizure free period rather than the required two year period when this survey was undertaken, it is important to ascertain whether there is any increased risk of injury associated accidents with this policy.

$(\Im$ Neurol Neurosurg Psychiatry 1996;60:621-627)

Keywords: epilepsy; road traffic accidents; driving

The occurrence of epileptic seizures or other episodes of loss of consciousness presently lead to the withdrawal of a driving licence. ${ }^{1}$ The epilepsy regulations differ from those governing other medical conditions in that they are specified by law. In the United Kingdom clinicians are not obliged by law to inform the Licensing Authority, but they do have a responsibility to counsel individual patients about the legal requirements to inform the DVLA.

The British driving licence states that:

"You are required by law to inform the DVLA, Swansea, SA99 1AT, at once if you have any medical disability which is or may become likely to affect your fitness to drive, unless you do not expect it to last for more than three months."

The reporting of one or more epileptic seizures to the DVLA will lead to that person's licence being revoked. In the case of a single seizure a reapplication can be made once 12 months have elapsed without further seizures. When a person reports more than one seizure a licence can be granted when the person can satisfy the following conditions for an ordinary driving licence which were effective at the time of our survey.

(a) he shall have been free from any epileptic attack during the period of one year immediately preceding the date when the licence is to have effect; OR

(b) he shall have had an epileptic attack while asleep more than 3 years before the date when the licence is granted and shall have had attacks only while asleep between the date of that attack and the date when the licence is granted; and

(c) The driving of a vehicle by him in pursuance of the licence is not likely to be a source of danger to the public.

The current driving regulations have gradually and empirically evolved over several years from an absolute prohibition against people with a history of epilepsy to the current more liberal approach. In 1948 Symonds $^{2}$ suggested that epileptic patients who had been free from attacks for a specified period should be able to state a case for being granted a licence. Hierons $^{3}$ considered that the liability to seizures was very small in a patient who had been free of them for three years while on medication and for another two years after discontinuing medication. After a ruling by a London stipendiary magistrate in 1964, that because a driver was being treated with antiepileptic drugs it did not mean that he had epilepsy, the requirement to be off antiepileptic drugs was generally dropped although there was considerable variability between different local authority licensing bodies until the motor vehicles (driving licences) regulations of 1970 specified a three year freedom from seizures before a valid driving licence could be held. The three year period has been steadily 
reduced until in August 1994 it was reduced to 12 months.

People with a history of epilepsy have their driving restricted because it is generally thought that such drivers would be at increased risk of accidents. Such a risk would be expected to increase due to the susceptibility to sudden episodes of loss of consciousness while driving, or due to the consumption of antiepileptic drugs which are known to have some effects on cognitive function, including concentration and reaction times. There are, however, very few studies which have considered the relative risk of accident rates in drivers with a history of epilepsy, and very few have considered this issue in a way that easily answers the question of when a driver with a history of epilepsy becomes an acceptable risk. $^{4-8}$ These studies have been of relatively small numbers of drivers and the way in which they have been selected has been unclear. None have given satisfactory information about clinical aspects of epilepsy in the drivers studied-in particular how remote was the last seizure from the time of the survey-and few studies have examined the severity of accidents which occur. The highest relative risk identified was $1 \cdot 95 .^{5} \mathrm{~A}$ more recent study suggested a relative risk of 1.33 in some 434 patients. $^{7}$ These relative risks do not differ from those of other less strictly regulated medical conditions ${ }^{5}$ and variables such as age and sex may have a greater influence on accident rates..$^{9}{ }^{10}$ This raises a question of whether current regulations are equitable to people with epilepsy..

We have recently estimated accident risks in a population of 661 patients counselled by neurologists in the United Kingdom because of recently diagnosed epileptic seizures or other episodes of loss of consciousness. This small sample showed a risk of accident in the previous year that was not different from that to be expected in a non-epileptic population with the same age and driving experience. ${ }^{8} \mathrm{~A}$ larger survey, however, has been undertaken of people with a valid driving licence and a history of single seizures or epilepsy. This report summarises the findings and compares accident rates with those of a non-epileptic population. The aims of the study were:

(1) To estimate the risks of vehicular accidents over a period of three years in drivers with a history of either single seizures or epilepsy, and compare them with the risks in a cohort of drivers followed up by the Transport and Road Research Laboratory (now Transport Research Laboratory-TRL).

(2) To identify demographic and clinical factors which influence the risk of accidents in people with epilepsy.

\section{Methods}

COHORT FROM THE NORMAL POPULATION In November 1987, 20000 drivers aged 23 years and over were sent questionnaires by post for self-completion. In February 1988, 10000 questionnaires were sent to drivers aged under 23 years. Response rates were
$63.6 \%$ and $71 \cdot 3 \%$ respectively. Excluding licence holders who had not driven in the previous year the final sample size was $18500 .^{10}$

A follow up survey was carried out in 1990-1. Questionnaires were sent to drivers who volunteered in the initial survey to help in further research. A total of 12324 such drivers received forms and the final number returned was 8888 , a response rate of $72 \%$.

The questionnaire used in the survey asked for basic demographic details (sex and age), year of passing the driving test (or approximate number of years driving, if uncertain), and information about (car and/or van) driving over the previous year (whether or not driven at any time, frequency of driving, and total miles driven). It also requested information about accident involvement as a driver during the previous three years.

\section{COHORT WITH SINGLE SEIZURES OR EPILEPSY}

The sample for this survey was gathered with the help of DVLA, Swansea and their associated medical department. Currently licences are issued to people with a history of epilepsy for a restricted period of up to three years. Towards the end of each licence period the DVLA contact the driver concerned to invite licence renewal. This is done routinely using a computerised system. Arrangements were made that a self completion questionnaire was sent out with each invitation for renewal from the DVLA (Morriston, Swansea). In this way some 24000 questionnaires were sent out during the course of a calendar year between June 1992 and May 1993. Of these forms 17036 were returned (a response rate of $71 \%$ ). In addition to these forms sent out routinely, the DVLA Medical Department at The Oldway Centre, Swansea receives notification from drivers with recent seizures. Questionnaires were also sent to such people during the same period: 468 forms were issued and 291 returned, a response rate of $62 \%$.

All forms were returned directly to the survey office in Liverpool by prepaid reply envelopes. The forms contained no personal identifiers.

The questionnaire sent to people with single seizures or epilepsy was based on the one used in the TRL survey, but supplemented with questions about the history of seizures; questions which were common to the two groups (those for whom data were provided by TRL) had an identical format. The supplementary questions were asked about the calendar years of the first, and of the most recent epileptic attack of any kind, as well as of the most recent attack while awake; whether the attacks were preceded by a warning or aura (and its nature), and any other medical condition or handicap. In addition, respondents were asked whether they were currently taking antiepileptic drugs. Information was requested about epileptic attacks, warnings, or auras while actually driving, and whether this had ever resulted in an accident.

\section{STATISTICS}

Variation in the risk of accidents between people arises from variation in the level of underly- 
ing risk factors, some of which have been identified and quantified in previous studies; it is important to adjust for these before drawing conclusions about comparative accident risks. To accomplish this we have employed a logistic regression model with occurrence of any accident during the previous three years as the (binary) dependent variable, and seven covariates in addition to an indicator for group (TRL or British Neurological Survey of Driving (BNSD)) membership. Of the seven covariates, sex was binary, driving during the previous year was categorical (table one lists the first five categories under this variable), and the remaining five were grouped continuous, the grouping being necessary to limit the total number of possible covariate patterns. The five were age in years, its square, annual mileage, years of driving experience, and its square. Age was included as a quadratic form to model the initial decline and subsequent rise in accident risk reported previously; years of driving experience were modelled in the same way to allow (non-monotonic) curvilinear effects, and annual mileage was logarithmically transformed to provide a monotonic (curvilinear) trend. Respondents with missing information on any of the key variables were excluded, thereby decreasing the sample sizes to 8670 for TRL (98\% of the total with known accidents) and 13201 (81\%) for BNSD. Risks are reported for unadjusted estimates, and after adjustment for imbalances between age, sex, driving experience, and annual mileage.

\section{Results}

CHARACTERISTICS OF SAMPLE

Information was available from 8888 respondents to the TRL survey and 16958 respondents to the neurological survey; the second comprised $16667(98 \%)$ with a history of epilepsy or single seizures applying to the DVLA for licence renewal, and 291 (2\%) licence applicants either -recently diagnosed or

Table 1 Demographic characteristics and driving habits in the two surveys

\begin{tabular}{|c|c|c|}
\hline & $\begin{array}{l}\text { TRL Sample } \\
n(\%)\end{array}$ & $\begin{array}{l}B N S D \\
n(\%)\end{array}$ \\
\hline Sex: & 8888 & 16958 \\
\hline Male & $4310(48)$ & $9219(54)$ \\
\hline $\begin{array}{l}\text { Female } \\
\text { Not known }\end{array}$ & $4578(52)$ & $\begin{array}{l}7708(46) \\
31(<1)\end{array}$ \\
\hline \multicolumn{3}{|l|}{ Age (y): } \\
\hline $\begin{array}{l}\text { Median } \\
(25,75 \text { th centiles }) \\
\text { Not known }\end{array}$ & $\begin{array}{l}32 \\
(22,52)\end{array}$ & $\begin{array}{l}38 \\
(29,49) \\
53(<1)\end{array}$ \\
\hline \multicolumn{3}{|l|}{ Driving experience $(y)$ : } \\
\hline $\begin{array}{l}\text { Median } \\
(25,75 \text { th centiles }) \\
\text { Not known }\end{array}$ & $\begin{array}{l}9 \\
(3,19) \\
60(<1)\end{array}$ & $\begin{array}{c}12 \\
(5,22) \\
2541(15)\end{array}$ \\
\hline \multicolumn{3}{|l|}{ Driven during past year: } \\
\hline No & $199(2)$ & $760(4)$ \\
\hline$<$ Once a week & $403(5)$ & 744 (4) \\
\hline About once a week & 305 (3) & 615 (4) \\
\hline Two or three times a week & $1746(20)$ & $2677(16)$ \\
\hline Every day & $6216(70)$ & $11753(68)$ \\
\hline Not known & $19(<1)$ & $409(2)$ \\
\hline \multicolumn{3}{|l|}{$\begin{array}{l}\text { Total miles driven in past year } \\
(\times 1000)\end{array}$} \\
\hline $\begin{array}{l}\text { Median } \\
(25,75 \text { th centiles })\end{array}$ & $\begin{array}{l}6 \cdot 0 \\
(2 \cdot 5,12)\end{array}$ & $\begin{array}{l}6 \cdot 0 \\
(2 \cdot 0,10)\end{array}$ \\
\hline Median (excluding not driven) & $6 \cdot 6$ & $6 \cdot 0$ \\
\hline $\begin{array}{l}\text { (25, } 75 \text { th centiles) } \\
\text { Not known }\end{array}$ & $\begin{array}{l}(2 \cdot 8,12) \\
153(2)\end{array}$ & $\begin{array}{l}(2 \cdot 5,11) \\
1288(7)\end{array}$ \\
\hline
\end{tabular}

relapsed. The last two groups are not differentiated in the analyses which follow. Table 1 summarises the characteristics and driving habits of the two samples. There was a slight preponderance of women in the TRL sample, and of men in the BNSD sample. Respondents to the BNSD were also slightly older despite the TRL survey being restricted to drivers aged 20 years and over. At the same time the BNSD sample had more driving experience (as measured by the interval between passing the driving test and the year of survey). The pattern of driving habits over the previous year was broadly similar in the two samples, with a slight excess of non-drivers in BNSD, and of everyday drivers in TRL; this was reflected in the annual mileages which indicated that drivers in the TRL survey drove about 500 miles per year more than those in the BNSD survey.

\section{ACCIDENTS IN THE PREVIOUS THREE YEARS}

Table 2 shows the distribution of the numbers of accidents in which respondents claimed to have been involved during the previous three years.

Those for the BNSD (column 3) were taken directly from the forms, but adjusted in 27 cases to ensure that this total number was not less than the number of reported accidents in a car or van, as well as the number of accidents involving physical injury to the respondent or other people. As the survey requested detailed information about the three most recent accidents in which respondents were involved as drivers during the previous three years, some limited cross checking of the actual number of accidents against the number for which details were provided was possible. Discrepancies were noted in 106 cases (for example, some detail of two accidents, but involvement claimed in a total of one). Although it is possible that the discrepancies arose from respondents providing details of accidents occurring before the three year survey period, this has not been assumed, and the recorded accident involvement figures have been increased to remove the discrepancies; the corrected figures are shown in the column 4 of table 2 . Correction resulted in the number of subjects

Table 2 Distribution of respondents by accident involvement during previous three years

\begin{tabular}{llrl}
\hline & TRL & \multicolumn{2}{l}{ BNSD } \\
\cline { 2 - 4 } No of accidents & $\begin{array}{l}\text { Sample } \\
n(\%)\end{array}$ & $\begin{array}{l}\text { Recorded } \\
n(\%)\end{array}$ & $\begin{array}{l}\text { Correctedt } \\
n(\%)\end{array}$ \\
\hline 0 & $6860(77)$ & $13349(81)$ & $13344(81)$ \\
1 & $1627(18)$ & $2410(15)$ & $2314(14)$ \\
2 & $316(4)$ & $505(3)$ & $500(3)$ \\
3 & $60(<1)$ & $107(<1)$ & $213(1)$ \\
4 & $11(<1)$ & $16(<1)$ & $16(<1)$ \\
5 & $10(<1)$ & $8(<1)$ & $8(<1)$ \\
6 & $3(<1)$ & $1(<1)$ & $1(<1)$ \\
7 & $1(<1)$ & 16396 & 16396 \\
Total known & 8888 & $562(3)$ & $562(3)$ \\
Not known & & 16958 & 16958 \\
Total & 8888 & $0 \cdot 23$ & 0.25 \\
mean & $0 \cdot 29$ & 0.30 & 0.35 \\
Variance & 0.37 & & \\
\hline
\end{tabular}

^Number of accidents stated on survey form.

†Number of accidents after adjustment for those for which detail provided-see text. 
Table 3 Distribution of respondents by accidents and extent of injury

\begin{tabular}{lcc}
\hline Accidents and injuries & TRL sample & BNSD \\
\hline No accidents in a car or van & $6905(78)$ & $13361(81)$ \\
Car or van accidents & $1983(22)$ & $3035(19)$ \\
Without physical injury & $1696(86)$ & $2566(85)$ \\
Slight physical injury & $202(10)$ & $285(9)$ \\
Serious physical injury & $82(4)$ & $164(5)$ \\
Extent of injury unknown & $3(<1)$ & $20(<1)$ \\
Subtotal known & 8888 & 16396 \\
Not known & & $562(3)$ \\
Total & 8888 & 16958 \\
\hline
\end{tabular}

Values in parentheses are percentages of subtotal known, except those in bold which are percentages of respondents involved in car/van accidents. Slight injury indicates cuts and bruises (for example), whereas serious injury was defined as

not involved in any accident decreasing by just five, whereas those involved in a single accident decreased by nearly 100 (4\%); the numbers involved in three accidents actually doubled.

Table 2 indicates that the proportion of subjects involved in an accident during the previous three years is slightly lower in the BNSD than in the TRL survey, giving an (unadjusted) odds ratio $(95 \%$ confidence interval $(95 \% \mathrm{CI})$ ) for the risk of accident involvement of 0.77 (95\% CI $0.72-0.83)$.

The (adjusted) odds ratio for the risk of accident involvement was $0.95 \quad(95 \% \mathrm{CI}$ $0.88-1.02$ ), indicating that much of the observed difference in accident involvement between the two groups may be explained by imbalance in the risk factors; the upper limit of the confidence interval excludes an enhanced risk of accident involvement associated with epilepsy or single seizures.

Apart from requesting information about the total number of accidents in which each respondent had been involved during the three years before the surveys, the questionnaires also asked how many accidents were in a car or van, and of those, how many involved physical injury to anyone. Table 3 shows the overall distribution. Ninety nine per cent of accidents reported in both surveys occurred in a car or

Table 4 Risk factors for accidents three years before the survey

\begin{tabular}{llll}
\hline Covariate & Any accident & $\begin{array}{l}\text { Injury producing } \\
\text { accident }\end{array}$ & $\begin{array}{l}\text { Serious physical } \\
\text { injury }\end{array}$ \\
\hline Has warning or aura & $1.08(0.99,1 \cdot 17)$ & $1 \cdot 16(0.95,1.41)$ & $1.34(0.96,1.87)$ \\
Taking antiepileptic drugs & $1.10(1.01,1.20)$ & $1.00(0.81,1.21)$ & $0.75(0.54,1.04)$ \\
Period seizure free > 3 years & $0.74(0.62,0.87)$ & $0.66(0.46,0.93)$ & $0.56(0.32,0.96)$ \\
\hline
\end{tabular}

Values are OR (95\% CI).

Table 5 Mortality statistics: 1992

\begin{tabular}{|c|c|c|c|}
\hline & Men & Women & Total \\
\hline $\begin{array}{l}\text { Deaths (E810-E819) } \\
\text { Deaths (E820-E825) } \\
\text { Total }\end{array}$ & $\begin{array}{r}2848 \\
45 \\
2893\end{array}$ & $\begin{array}{r}1210 \\
11 \\
1221\end{array}$ & $\begin{array}{r}4058 \\
56 \\
4114\end{array}$ \\
\hline $\begin{array}{l}\text { Estimated population } \\
\text { aged } 20-79 \text { years }(\times 1000) \\
\text { Deaths } / 100000 / y\end{array}$ & $17851 \cdot 2$ & $18480 \cdot 1$ & $\begin{array}{c}36331 \cdot 3 \\
11 \cdot 32\end{array}$ \\
\hline $\begin{array}{l}\text { Total } \\
\text { No accident information } \\
\text { Accident information } \\
\text { Expected fatalities } \\
\text { Observed (reported) }\end{array}$ & $\begin{array}{c}\text { TRL sample } \\
8888 \\
-\quad \\
8888 \\
-\quad 3.0\end{array}$ & $\begin{array}{c}B N S D \\
16958 \\
562 \\
16396 \\
5 \cdot 6 \\
12\end{array}$ & \\
\hline
\end{tabular}

Source: series DH4 No $18 .{ }^{13}$ van, and most of these did not involve physical injury to drivers or other road users. Of 1983 respondents to the TRL survey involved in car or van accidents, $14 \%$ were involved in physical injury accidents; this compares with $15 \%$ out of 3035 in the BNSD. The odds on involvement in an injury accident, given involvement in any car/van accident was similar in the two surveys (odds ratio (BNSD/TRL): 1.08 (95\% CI 0.91-1.27)). Adjustment of the risk of injury accidents in the two surveys for the set of seven covariates used previously gave an odds ratio of $1 \cdot 1$ (95\% CI $0 \cdot 91-1 \cdot 3)$. These results rule out an increased risk of accidents involving physical injury of $30 \%$ or greater in the BNSD, but the number of such accidents is insufficient to allow greater refinement.

In total, 246 respondents were involved in at least one accident resulting in serious physical injury (defined as needing hospital care), as opposed to slight injuries (such as cuts and bruises); these constitute just under $5 \%$ of respondents known to have been involved in an accident in a car or van, and under $1 \%$ of the 25284 respondents for whom accident information was available. Of the 1980 respondents to the TRL survey involved in car or van accidents (and for whom the extent of injuries was known), $4 \%$ were accidents resulting in serious physical injuries; this compared with $5 \%$ out of 3015 in BNSD. The odds on involvement in an accident resulting in serious physical injuries, given involvement in any accident are higher in BNSD than in TRL (odds ratio: $1.33(95 \%$ CI $1 \cdot 01-1 \cdot 76), \chi^{2}=$ $4 \cdot 3, \mathrm{df}=1, \mathrm{P}<0.05)$.

\section{RISK FACTORS FOR ACCIDENTS IN DRIVERS} WITH EPILEPSY

Although some information was collected from patients to try and classify the types of seizures they had had, this information did not seem reliable enough to be entered into any analyses examining specific risk factors for accidents. A total of 8018 (47\%) of the sample described attacks without an aura, and 7055 $(42 \%)$ were not taking antiepileptic drugs. The median time from first to last seizure was short, four years (25th, 75th centiles 1,10 years), whereas the median time elapsed from the last seizure to the survey was long, 11 years (25th, 75th centiles 6, 18 years). Ninety four per cent of drivers had never had a warning or a seizure while driving but two thirds of those who had experienced such a warning or seizure did not have an accident in association with it.

To investigate factors affecting the risk of any accident, the risk of an accident producing an injury, and an accident resulting in serious physical injury during the three years before the survey three logistic regression analyses have been performed with the occurrence of the respective accident (yes or no) as the dependent variable. In the analysis shown in table 4 sex, age and its square, annual mileage, and driving frequency during the previous year were fitted first, followed by just one of the other covariates in turn. The effect of individual covariates on the risk of accidents is therefore 
Table 6 Accident rates

\begin{tabular}{|c|c|c|c|c|}
\hline & \multicolumn{2}{|l|}{$T R L$} & \multicolumn{2}{|l|}{$B N S D$} \\
\hline Estimated total $\mathrm{km}$ & \multicolumn{2}{|c|}{126316083} & \multicolumn{2}{|c|}{217530319} \\
\hline $\begin{array}{l}\text { Slight injury } \\
\text { Serious injury/fatal } \\
\text { Fatality } \\
\text { All }\end{array}$ & \multicolumn{4}{|c|}{$\begin{array}{l}\text { Casualty rates per } 100 \text { million vehicle } \mathrm{km} \text { (1992) } \\
62 \cdot 2\end{array}$} \\
\hline & \multicolumn{4}{|c|}{$\begin{array}{l}\text { No of respondents in accidents over three years } \\
T R L\end{array}$} \\
\hline $\begin{array}{l}\text { Slight injury } \\
\text { Serious injury/fatal } \\
\text { Fatality } \\
\text { All }\end{array}$ & $\begin{array}{c}\text { Expected } \\
235 \cdot 7 \\
49 \cdot 0 \\
3 \cdot 9 \\
284 \cdot 7\end{array}$ & $\begin{array}{l}\text { Observed } \\
202 \\
82 \\
0 \\
284\end{array}$ & $\begin{array}{c}\text { Expected } \\
405 \cdot 9 \\
84 \cdot 4 \\
6 \cdot 7 \\
490 \cdot 3\end{array}$ & $\begin{array}{l}\text { Observed } \\
285 \\
164 \\
12 \\
449\end{array}$ \\
\hline
\end{tabular}

Source Ackroyd. ${ }^{14}$ predicted from the age and driving experience of the population. ${ }^{8}$

Our estimates of the relative risk of all types of accidents in this sample seem to be at the lower end of a range of relative risks identified by other authors. Hormia ${ }^{11}$ reported a Finnish population with an accident rate between 1.3 and twice that of matched controls. Crancer and $\mathrm{McMurray}^{6}$ noted an increased risk in a population of epileptic drivers in Washington State. The increased relative risk, however, was overshadowed by other risk factors such as sex. Keys et $a l^{12}$ studied a Wisconsin population of 3333 licenced drivers with epilepsy and found an accident rate of $29 \%$ as compared with $20 \%$ in the control group. Waller ${ }^{5}$ found a relative risk for accidents of 1.95 but the risk ratio for cardiovascular disease was 1.62 , diabetes $1 \cdot 78$, and mental illness $2 \cdot 12$. Hansotia and Broste $^{7}$ found a relative risk of accidents of 1.33 for epilepsy and, as in our study, estimated a higher risk for accidents producing injury of 1.57 . A lower estimate of risk could be explained by the relatively long duration of freedom from seizures in our cohort.

The nature of the study might have led to some systematic underreporting by the population of the people with epilepsy to ameliorate current restrictive driving regulations and we cannot exclude this possibility. We would argue that the inclusion of a control group and the willingness of the epilepsy group to report the excess of accidents producing serious and fatal injury make the possibility of these results being artefactual somewhat less likely.

Overall, in both surveys the risk of an accident involving physical injury to the driver or any other person is about $1 \%$ per year. However, the survey does provide some evidence that the risk of injury induced by road traffic accidents is increased in the BNSD sample. Thus the adjusted relative risk for being involved in an accident resulting in injury is $1 \cdot 1$ (95\% CI $0 \cdot 91-1 \cdot 3)$. Serious physical injuries resulting in admission to hospital occurred in $4 \%$ of all accidents from the TRL sample but $5 \%$ of the BNSD sample. The adjusted odds ratio for the risk of serious injury was $1.37(95 \%$ CI $1 \cdot 02-1 \cdot 84)$. None of the accidents recorded in the TRL survey resulted in fatality but 12 such accidents were recorded in the BNSD sample. Comparison of relative fatalities in this study is not straightforward. Both the TRL and BNSD surveys collected retrospective data by self completion questionnaires and so can draw no conclusions about fatalities to drivers themselves. The absence of any accidents resulting in fatalities from the TRL sample is puzzling as it comprises nearly 27000 driver-years.

To examine these issues further we have tried to determine the expected rate of accidents resulting in fatalities for the TRL and the BNSD samples. The conclusions must be tentative because we are not looking at fatality rates in a defined sample. Obviously respondents must be alive to return a questionnaire and so cannot be fatalities; these must be people with whom drivers came into "vehicular contact". As the absence of any reported fatal- 
ities in the TRL sample does not allow us to calculate a relative risk, we have examined two sources of information. The first is derived from the Registrar General's Annual Report published by OPCS ${ }^{13}$ entitled Mortality statistics: injury and poisoning. It tabulates death from road traffic accidents by International Classification of Diseases (ICD) codes, grouped by age, sex, and ICD numbers (E810-E829). The figures are actually broken down as drivers, passenger, motorcyclist, passenger on motorcycle, cyclist, and pedestrian. Table 5 shows the total number of deaths in 1992 over all ages from motor vehicle accidents. Codes E810-E819 include deaths from motor vehicle traffic accidents involving cars, motorcycles, riders of animals, cyclists, pedestrian, and unspecified; codes E820-E825 refer to motor vehicle non-traffic accidents (principally not on public highways). Codes E826-E829, which do not involve motor vehicles, have been excluded. Table 5 shows the estimated population of England and Wales in 1992 aged 20-79 years. Annual deaths per 100000 population are then estimated and used to compute expected numbers reported in the two surveys over a three year period. There is an excess of expected fatalities in the TRL sample, and observed fatalities in the BNSD sample, in which there are about twice as many observed fatalities as expected.

Ackroyd's General review of personal injury road accidents in Great Britain in $1992^{14}$ publishes casualty rates per 100000000 vehicle$\mathrm{km}$. Table 6 shows the estimated total miles driven. These have been calculated for all respondents for whom accident data were available. Three adjustments were made:

(1) Recorded annual mileage in excess of 100000 miles was recoded to 100000 miles.

(2) When annual mileage was not known but respondent was known to have driven during the previous year it was estimated by the median for the corresponding group.

(3) when respondent was known not to have driven during the previous year annual mileage was estimated as two thirds of the median, equivalent to driving median mileage per year for two years and then stopping for the third.

The casualty rates reported were then used to estimate the number of respondents who have accidents during three years of the survey. The middle section of table 6 shows the rates which have been used; the bottom section shows expected and observed numbers in accidents of various types. Remarkably the observed and expected totals were identical for all accidents for the TRL sample but were about $8 \%$ less in the BNSD sample than would be expected. For serious or fatal accidents almost twice the expected numbers were observed in the BNSD sample. Once again this method of calculation shows that about four fatalities would have been expected in the TRL sample though none were found. It should be noted that both methods of estimating the expected fatalities were in good agreement. We are therefore reasonably confident that a population of drivers with a history of epilepsy has an increased risk of involvement in accidents resulting in serious injury or fatality and that this increase is of the order of $40 \%$ (by comparison with the TRL sample) to $100 \%$ (by comparison with data from the General review of personal injury road accidents in Great Britain in 1992). Our information on accidents excludes driver fatalities because of our retrospective methodology. It seems likely that this will also be increased in drivers with a history of epilepsy, a view that is supported by Taylor, ${ }^{15}$ who found a higher than expected presence of antiepileptic drugs in the blood of drivers killed in road traffic accidents.

The second important issue relevant to the licensing of drivers with a previous history of epilepsy is whether it is possible to identify subgroups of such drivers who might be at higher risk of involvement in accidents and most particularly accidents that result in serious injury or fatality. The preceding discussion emphasises that it would be most important to identify factors resulting in an increased risk of accidents associated with serious injury, but of course the smaller numbers of such accidents mean that the possibilities for identifying predictive factors will be less. In an exhaustive unselected analysis of all possible factors that might affect accident rates there are very few clinical factors which impact on overall risks. This is not unexpected as the risk of any kind of accident does not seem very different in a population of drivers with epilepsy from those surveyed by TRL.

From the licensing point of view three issues might be of particular importancenamely, whether or not a person is taking antiepileptic drugs, whether or not a person's self reported attacks are usually associated with a warning, and how close the history of active epilepsy is to the period for which a licence is granted.

Questions have been raised about the possible cognitive effects of antiepileptic drugs on motor reaction times, vigilance, and coordination. Our survey does not suggest that taking antiepileptic drugs in any way increases the risks of any form of accident in a population of drivers with a history of epilepsy (odds ratio: 0.97 (95\% CI 0.87-1.07)).

People with epilepsy who have a warning or aura before their attacks commonly claim to be in a position to stop a motor vehicle in the event of such a warning or aura occurring. Our data do not support this contention with respect to accidents overall or to accidents associated with serious injury or fatality.

Our analysis of the relation of seizures to the risk of accidents does, however, show a clear effect. The absence of seizures within the three year period covered by a questionnaire seems to halve the risk of serious injury or fatal accident indicating that the occurrence of seizures within the survey period accounts for much of the excess risk of such accidents in our population. Unfortunately the methods that we have used do not tell us whether any particular period of freedom from seizures could be used to reduce this risk. Given that the most important factor in predicting the occurrence of seizures in patients in remission 
of epilepsy-whether or not antiepileptic drugs are discontinued-is the period of time since the last seizure (the longer the remission, the less the risk of seizures ${ }^{16}$ ), the licensing of drivers with a history of epilepsy will have to remain dependent on this factor. In this MRC study, the risk of recurrence of seizures is not linearly related to the seizure free period. It declines in an exponential way so that there is little change in risk of recurrence after five years free of seizures. The study only recruited patients who had been seizure free for two years or greater so that there is no way of predicting risks of seizure recurrence after shorter episodes of remission such as the one year now allowing a return to driving under recently revised regulations. We have recently analysed data on 409 people in the MRC Study of Antiepileptic Drug Withdrawal who had a further seizure during the course of this study, so as to look at the risk of further seizures, after the first recurrence, conditional on the passage of various periods of time. ${ }^{17}$ This suggests that once two years has elapsed after a recurrence, the risk of seizures in the next 12 months is about $15 \%$. However, if only 12 months have elapsed since the last seizure the risk of a further seizure in the next 12 months is about $20 \%$.

What then are the implications of this study for the current driving regulations? The survey was undertaken at a time when a two year seizure free period was necessary to obtain a driving licence. In August, 1994 this qualification period was reduced to 12 months. The question must arise as to whether this relaxation in the regulations carries an acceptable risk to the community. Given that the current approach allows young people under the age of 25 to drive despite the fact that they have a threefold to fourfold increase of any accident and accidents producing serious injury, ${ }^{10}$ the increased risk of seizures during a period of driving accepted by shortening the period of seizure free qualification from 24 months to 12 months is probably acceptable, but is a subject that demands further study.

The work was completed with the support of a contract from the Transport Research Laboratory. We are grateful to all those who returned the questionnaires. Sue Brown and Barbara who returned the questionnaires. Sue Brown and Barbara Eaton gave clerical support to the study. We are grateful to Advisory Branch of the DVLA for their enthusiastic cooperaAdvisory Branch of the DVLA for their enthusiastic coopera-
tion. Dr John Irvine, Dr Philip Jones, and Dr Peter Lyne gave tion. Dr John Irvine, Dr Philip Jones, and Dr Peter Lyne gave
advice about the questionnaire. Ann Jacoby of the Centre for advice about the questionnaire. Ann Jacoby of the Centre for
Health Services Research, University of Newcastle-upon-Tyne helped in the design of the questionnaires.

1 DVLA. At a glance guide to current medical standards of fitness to drive. Swansea: DVLA, 1993

2 Symonds C. Epilepsy. BMF 1948;1:533.

3 Hierons R. Driving and epilepsy. BMF 1956;1:206.

4 Naughton TJ, Waller J. Feasibility of developing a medical condition collection system for driver licensing. Washington, DC: National Highway Safety Administration. Washington, DC: National Highway Safety Administration.
US Dept of Transportation publication DOT HS 1980: 805-95.

5 Waller JA. Chronic medical conditions and traffic safety. $N$ Engl f Med 1965;273:1413-20.

6 Crancer A, McMurray L. Accident and violation rates of Washington's medically restricted drivers. $\mathcal{F} A M A$ 1968; 205:74-9.

7 Hansotia P, Broste SK. The effect of epilepsy or diabetes mellitus on the risk of automobile accidents. $N$ Engl $\mathcal{f}$ Med 1991;324:22-6.

8 Taylor J, Chadwick DW, Johnson T. Accident experience and notification rates in people with recent seizures, epilepsy or undiagnosed episodes of loss of consciousness. $Q \mathcal{F}$ Med 1995;88:733-40.

9 Broughton J. The variation of car drivers' accident risk with age. Crowthorne: Transport and Road Research age. Crowthorne: Transport and

10 Maycock G, Lockwood CR, Lester JF. The accident liability of car drivers. Crowthorne: Transport and Road Research Laboratory, 1991. (Department of Transport TRRL Report RR315.)

11 Hormia A. Does epilepsy mean a higher susceptibility to traffic accidents? Acta Psychiatr Scand 1961;150:210-2.

12 Keys JB, Martin CJ, Barrow EL, Fabing HD. The epileptic automobile driver in Ohio. Ohio State Medical fournal 1961;57:1127-31.

13 Office of Population Census and Surveys. Mortality statistics: injury and

14 Ackroyd R General review of personal injury road accidents in Great Britain in 1992. Road accidents Great Britain 1992. The casualty report. London: HMSO, 1992.

15 Taylor JF. Epilepsy and other causes of collapse at the wheel. In: Godwin-Austen RB, Espir MLE, eds. Driving and Epilepsy. RSM International Congress Series. London: RSM, 1988;60:5-7.

16 Medical Research Council Antiepileptic Drug Withdrawal Study Group. Randomised study of antiepileptic drug withdrawal in patients in remission. Lancet 1991;337: 1175-80. 